\title{
Natural Disaster and Risk of Psychiatric Disorders in Puerto Rican Children
}

\author{
Erika Felix • Lino A. Hernández • Milagros Bravo • \\ Rafael Ramirez • Jose Cabiya • Glorisa Canino
}

Published online: 15 January 2011

(C) The Author(s) 2011. This article is published with open access at Springerlink.com

\begin{abstract}
We examined the persistence of psychiatric disorders at approximately 18 and 30 months after a hurricane among a random sample of the child and adolescent population (4-17 years) of Puerto Rico. Data were obtained from caretaker-child dyads $(N=1,886)$ through in person interviews with primary caretakers (all children) and youth (11-17 years) using the Diagnostic Interview Schedule for Children IV in Spanish. Logistic regressions, controlling for sociodemographic variables, were used to study the relation between disaster exposure and internalizing, externalizing, or any disorder. Children's disaster-related distress manifested as internalizing disorders, rather than as externalizing disorders at 18 months post-disaster. At 30 months, there was no longer a significant difference in rates of disorder between hurricane-exposed and non-exposed youth. Results were similar across age ranges. Rates of specific internalizing
\end{abstract}

\author{
E. Felix $(\bowtie)$ \\ Gevirtz Graduate School of Education, University of California, \\ Santa Barbara, \\ Santa Barbara, CA 93106-9490, USA \\ e-mail: efelix@education.ucsb.edu \\ L. A. Hernández $\cdot$ M. Bravo $\cdot$ R. Ramirez $\cdot$ G. Canino \\ Behavioral Sciences Research Institute, University of Puerto Rico, \\ Medical Sciences Campus, PO Box 365067, San Juan, \\ Puerto Rico 00936-5067

\section{Bravo} \\ e-mail: mbravo@rcm.upr.edu \\ R. Ramirez \\ e-mail: rramirez@rcm.upr.edu \\ G. Canino \\ e-mail: glorisa.canino@upr.edu \\ J. Cabiya \\ Carlos Albizu Univeristy, \\ San Juan, Puerto Rico \\ e-mail: jcabiya@albizu.edu
}

disorders between exposed and unexposed children are provided. Research and clinical implications are discussed.

Keywords Natural disasters $\cdot$ Psychiatric disorders $\cdot$ Child and adolescent $\cdot$ Latino youth $\cdot$ Trauma

\section{Introduction}

Disasters occur once a day on average in the world (International Strategy for Disaster Reduction, n.d.). As traumatic events, they are potentially strong stressors due to their disruptive nature, high extent of impact, production of terror and horrors scenes, undesirable and uncontrollable occurrences, and prolonged alterations in the social and material environment (Davidson and Baum 1986). The scientific understanding of the impact of disasters on child and adolescent psychological functioning has greatly increased in recent times and various excellent recent reviews of the literature have been published (e.g., La Greca et al. 2002; Norris et al. 2002a, b). When children experience a life-threatening disaster, they may show a wide range of psychological reactions, especially symptoms of post traumatic stress disorder (PTSD), depression, generalized anxiety and pathological grief reactions (La Greca et al. 1998; Vogel and Vernberg 1993; Weems et al. 2007, 2010; Yule 2001).

An important clinical issue regarding psychological responses to disasters is the persistence of these reactions. Existing evidence indicates that youth who are heavily exposed to a disaster may experience psychological distress that may last for years after the event (Vogel and Vernberg 1993). For some children who experience catastrophic levels of trauma exposure in these events, initial posttraumatic stress (PTS) symptoms common in PTSD and separation anxiety often develop over time into serious 
levels of depression (Vernberg 2002). Generally, a decline in symptomatology is observed over the first years following natural disasters (La Greca and Prinstein 2002). However, following Hurricane Katrina, studies on children and adults show an increase in PTS, anxiety, and distress symptoms over time, possibly due to prolonged stress in the recovery context (Kessler et al. 2008; Weems et al. 2010).

Although these advancements in the scientific understanding of the impact of natural disasters on youth functioning are significant, research is still needed in some important areas, which this study can address. Most child disaster studies examine PTS and/or depression symptoms. However, reactions may include other internalizing disorders and the acting out, aggressive, and delinquent behaviors associated with externalizing reactions to stress. These reactions may persist for long periods of time for some children. For example, Weems and colleagues (2010) found mental health problems among youth survivors at 24 and 30 months post-Hurricane Katrina. In addition, how the types of trauma reactions may vary by the age of the child needs further exploration, but most studies of child survivors of disasters have had a limited age range. Thus, to better understand the range of traumatic reactions among children and youth, a wide range of psychopathology needs to be assessed across age ranges.

Likewise, few studies have investigated if psychological post-disaster reactions meet criteria for a disorder, which our study can address. This line of research is needed to distinguish "normal" or adaptive reactions, which are likely selfcorrective, from what could be considered "pathological" effects that require intervention (La Greca and Prinstein 2002). Most studies examine symptoms only, and fail to assess for psychosocial impairment, although DSM-IV includes it as a criterion in the classification of disorders. The consideration of this criterion would make disaster studies more reflective of clinical reality, since the impairment that results from symptoms is what usually leads to a child being referred to services rather than the mere manifestation of symptoms (Angold et al. 1999). La Greca and Prinstein (2002) acknowledged, however, that the disaster studies they reviewed did not assess impairment of youth's functioning.

The few studies that have examined the reaction of children and adolescents to disasters at the disorder-level have mainly focused on the presence of PTSD related to the post-disaster time (3 months to 1 year), reporting rates that fluctuate between 2\% and 7.3\% (La Greca and Prinstein 2002). However, the persistence of these disorders through time has not been studied since the use of longitudinal designs involving multiple assessments post-disaster is sparse.

\section{Conceptual Model of Post-Disaster Trauma Reactions}

Rather than merely documenting that exposure to disasters evokes symptoms and disorders, disaster studies need to identify factors that influence the development and maintenance of disaster-related reactions in children and adolescents. To guide this research and organize its findings, a conceptual model (e.g., Silverman and La Greca 2002; Vernberg et al. 1996) has been developed to overcome the atheoretical nature of many studies in the field. The model presented by Vernberg, La Greca and colleagues (La Greca et al. 1996, 1998; Silverman and La Greca 2002, Vernberg et al. 1996) proposes that aspects of the disaster experience (e.g., life threat, loss \& disruption), along with preexisting child characteristics (e.g., demographic characteristics \& pre-disaster functioning), influence efforts to cope with the events. Efforts to cope have a reciprocal relationship with PTS symptoms. Exposure to traumatic events influences aspects of the post-disaster recovery environment (e.g., social supports and major life events or stressors) which also has a reciprocal relationship with efforts to cope with events. The authors found empirical support for their model in predicting PTSD after Hurricane Andrew, but further research is needed in order to look at other psychiatric disorders within other populations.

In support of the model, research shows that the more children perceive their lives, or the lives of loved ones to be threatened, the closer proximity to the event, and greater loss, the higher the report of PTS symptoms (Silverman and La Greca 2002). This is likely true for other internalizing disorders, and may extend to externalizing problems as well. Conversely, children who do not perceive their lives or loved ones lives to be at danger, or who do not experience significant loss, may not report PTS symptoms following a disaster. In terms of pre-existing child characteristics, some research indicates that being female, younger, and/or having prior psychosocial or learning problems are related to higher post-disaster PTS (La Greca and Prinstein 2002; Silverman and La Greca 2002). For young children, it is unclear if the risk stems from developmental differences in younger children's perceptions of disaster trauma, or from the tendency of young children to engage in behavior that is more readily identifiable by caregivers as distress (e.g., trauma-themed play La Greca and Prinstein 2002). In contrast, Norris et al. (2002a, b) report that among the child and adolescent studies they reviewed, the findings on age were inconsistent. They also report that poverty is a risk factor for worse post-disaster functioning, perhaps due to greater exposure or less resources to facilitate recovery.

In the present study we focus on aspects of the disaster experience and pre-existing child characteristics. For the former, it is known that the extent and intensity of exposure is key to predicting children's psychological reactions (La Greca et al. 2002). Whether this holds after more than a year has passed has rarely been studied with youth. But as recovery can be prolonged, mental health outcomes can persist (e.g., Weems et al. 2010). We examine this at 18 and 
30 months post-disaster, and have an unexposed comparison group. We also explore the influence of gender, age, and poverty status for internalizing and externalizing disorders. Females may have been more at risk in past studies because PTS or other internalizing disorders were examined. A different result may emerge with the inclusion of externalizing problems. A wide age range was assessed in this study and the functioning of younger (age 410 years) and older (age 11-17 years) can be assessed. As prior findings have been equivocal (Norris et al. 2002a, b), and most studies do not have a large age range, this study can assist in clarifying this relationship at a basic level. Financial strain, as a pre-existing demographic characteristic, is also explored. Poverty level is already high in this sample; however the perception of poverty can influence ability to recover.

\section{Post-Disaster Distress Among Latino/as}

Our study assesses the range of psychiatric disorders post-disaster among Puerto Rican children and youth. How our findings potentially generalize to other U.S. populations, including mainland Puerto Ricans, is important to consider. Thus, we briefly summarize relevant research that can guide the interpretation of our findings and lends some support to the ability to generalize the results. As the cross-ethnic research on youth mental health following a natural disaster is scant, we review many types of studies, including those on adults, studies following terrorism, and general cross-ethnic studies of youth mental health.

In their review of the literature, Adams and Boscarino (2005) noted inconsistent findings when Latino and White adults were compared on rates of PTSD following the 9/ 11/01 World Trade Center attack. After adjusting for demographics, stressors, and stress moderators, they report little support for the idea that Latinos may suffer from worse mental health following a disaster than Whites. In contrast, Perilla et al. (2002) found that White survivors of Hurricane Andrew showed the lowest rates of PTSD, whereas Spanish-preferring Latino/as showed the highest rates. However, this could partially be explained by differential exposure as the Latino/a group had greater exposure. Child disaster studies have also explored the role of ethnicity, exposure, and post-disaster mental health. Vernberg and associates (1996) did not find an effect for ethnicity on PTS symptoms. Overall, these findings support that the rates in a Latino population are likely similar to other populations if level of exposure is similar and demographic characteristics, for example socioeconomics, are controlled.

Issues of the influence of acculturation and cultural stress on mental health are also important to consider in terms of generalizability. The hypothesis that Puerto Ricans living on the mainland US may differ from those living in Puerto Rico (PR) on mental health due to differences in acculturation and cultural stress was explored by Duarte and colleagues (2008). Using two samples of Puerto Rican youth (one group living in South Bronx, the other in PR), the same measures and methods, they found that the influence of acculturation and cultural stress on psychiatric symptoms was similar for mainland and island-bound Puerto Rican youth. Consequently, this also lends some support to the generalizability of the findings of this current study to mainland populations.

\section{Current Study}

An unusual opportunity arose in 1998 in the Spanishspeaking Caribbean island of PR to study some of the issues previously mentioned, especially the persistence of disorders in the post-disaster period. A longitudinal twowave epidemiological study was already planned and funded to study psychopathology and mental health services in a random sample of the island's population of children and adolescents when Hurricane Georges struck. At the time, a pilot study to assess the psychometric properties of the instruments was on the verge of starting and data collection for the survey's first wave began a year later. Hurricane Georges hit the Caribbean and Eastern United States as a category two hurricane, in late September 1998. Two days after it struck PR, many communities reported property damage, 416 government shelters were opened for approximately 28,000 persons, 700,000 persons were without water and $1,000,000$ had no electricity for some time (Center for Disease Control and Prevention 1998). The destruction left many families affected psychologically. For example, in the eastern part of the island, 2,238 individual cases were reported as receiving crisis counseling in a 3-week period, including approximately 467 cases of children that were exhibiting acute reactions to stress (Prewitt 1999). Although PR regularly experiences tropical storms, a hurricane hitting the island is a rarer event, compared to the frequency in which hurricanes inundate Florida, for example. To date, a hurricane has not hit the island since Hurricane Georges. Prior to Hurricane Georges, the last hurricane to strike the island was Hurricane Hugo, which made landfall in September, 1989. Thus, the level of devastation experienced by the children and families in this study is beyond what they experience in a regular hurricane season.

The present study, due to its inception in a large, comprehensive two-wave study, overcomes some methodological limitations identified in the disaster literature (Norris et al. 2006; La Greca et al. 2002). The availability of a large random sample of the population enables the 
comparison of exposed and unexposed groups and the use of control variables in the analysis to better study the disaster-disorder relationship; it also allows for the detection of interaction effects. This study examined the persistence of post-disaster disorders in youth (4-17 years old), at approximately 18 (T1) and 30 (T2) months postdisaster. We predicted that greater hurricane exposure would be related to internalizing, externalizing, and any psychiatric disorder at both 18 and 30 months post-disaster. Given the large age range, we assessed for differential affects by age group (ages 4-10 years and 11-17 years). We could not divide the age range further due to loss of statistical power. We explored the moderating effects of preexisting characteristics of the child (i.e., sex, age) and the family (poverty level) in the youth's disaster response. Finally, we provide frequencies for specific disorders if there was significant relation between exposure and the higher rank disorder categories.

\section{Methods}

\section{Participants}

Children aged 4 to 17 years were selected from an islandwide probability household sample. This sample and the methods of the study have been described in detail elsewhere (Canino et al. 2004). Briefly, the sample was stratified by PR's health reform area, urban and rural area, child's age, and sex using US 1990 Census' block groups as primary sampling units. These units were classified according to economic level and size, grouped into block clusters and further classified as urban or rural. Three hundred block clusters were randomly selected and then divided into two random replicates. A household was selected for inclusion in the study if it had children between the ages of 4 to 17 . One child was selected at random from each household using Kish Tables (1965) adjusted for age and sex. Out of 2,102 eligible households, 1,886 parentchild dyads were successfully interviewed for a total completion rate of $90 \%$ at $\mathrm{T} 1$. The follow-up was conducted with $94 \%$ of the 1,886 parent-child dyads. T1 took place from September 1999 to December 2000 (50\% of interviews had been completed by late May, 2000). T2 was scheduled for at least a year after the first assessment and occurred from October 2000 to December 2001 (50\% of interviews had been completed by late April, 2001). The sample was weighted to represent the general population in the year 2000. The weights correct for differences in the probability of selection because of the sampling design.

Table 1 shows the demographics characteristics of the sample at $\mathrm{T} 1$ and $\mathrm{T} 2$ after post-stratification by age and sex according to the 2000 US census. The final sample of 1,886 children at $\mathrm{T} 1$ constituted a sampling fraction of approximately 2.2 per 1,000 children in the population.

\section{Measures}

We used a multi-stage method for cross-cultural adaptation and translation of study measures derived from the medical, sociological and psychological literature (Bullinger et al. 1998; Brislin et al. 1973). Our research team has used this method on multiple occasions to create measures that were both culturally and linguistically appropriate. The result was a translated version of the instrument that tackles the major dimensions of cross-cultural equivalence: content, semantic, technical, criterion and concept equivalence (Canino and Bravo 1994; Bravo et al. 1991; Matías-Carrelo et al. 2003).

Demographic Characteristics Interview information was obtained on demographic characteristics. Perception of poverty was used in the analyses because prior research with this sample showed that income was not related to prevalence of a mental disorder (Canino et al. 2004), perhaps because much of the island's population would be classified as low income. However, there was much variability within this group, thus participants' perceptions of whether they live well, paycheck to paycheck, or live poorly were used.

\section{Diagnostic Interview Schedule for Children (DISC-IV)}

Last-year DSM-IV psychiatric disorders were assessed using the latest translation into Spanish of the DISC-IV (Bravo et al. 1991, 2001), with parallel youth and parent interview versions. The test-retest reliability of the DISCIV has been reported in both Spanish and English-speaking clinic samples yielding comparable results (Bravo et al. 2001; Shaffer et al. 2000). Kappas for parent report in an outpatient sample in Puerto Rico range from 0.42 to 0.70 , indicating acceptable reliability. Procedures for Spanish translation and back translation are documented in the work of Bravo and colleagues (1991, 2001). Children younger than 11 years were not interviewed with the DISC-IV because there is evidence that their reports would not be reliable (Schwab-Stone et al. 1994). Thus, for children age 4-10 years, parent DISC-IV interview was used, which is consistent with prior research (Canino et al. 2004).

The DISC-IV scoring algorithms included functional impairment and distress associated with each diagnosis. In this study, three "higher rank" diagnostic measures were mainly used due to low $\mathrm{N}$ for most disorders: Any disorder, any externalizing disorder and any internalizing disorder. Any disorder refers to meeting criteria during the last year for any of the DSM-IV diagnoses studied, evaluated on the basis of either parent or child reports. Externalizing 
Table $1 \mathrm{~T} 1$ and T2 demographic characteristics of children compared to the 2000 US Census

\begin{tabular}{|c|c|c|c|c|c|c|c|}
\hline \multirow[t]{2}{*}{ Demographics } & & \multicolumn{2}{|c|}{ Sample at T1 } & \multicolumn{2}{|c|}{ Sample at T2 } & \multicolumn{2}{|c|}{2000 Census } \\
\hline & & $n$ & Weighted $\%$ & $n$ & Weighted\% & $n$ & $\%$ \\
\hline \multirow[t]{2}{*}{ Sex } & Male & 982 & 51.1 & 920 & 50.8 & 438,540 & 51.1 \\
\hline & Female & 915 & 48.9 & 868 & 49.2 & 419,202 & 48.9 \\
\hline \multirow[t]{2}{*}{ Age } & $4-10$ & 986 & 50.2 & 794 & 42.9 & 431,004 & 50.2 \\
\hline & $11-17$ & 911 & 49.8 & 994 & 57.1 & 426,738 & 49.8 \\
\hline \multirow[t]{3}{*}{ Poverty level } & Live well & 1,033 & 51.4 & 1,015 & 56.5 & - & - \\
\hline & Chk to chk & 618 & 33.7 & 546 & 30.55 & - & - \\
\hline & Live poorly & 266 & 15.0 & 227 & 12.95 & - & - \\
\hline
\end{tabular}

disorders refer to the presence of any disruptive disorder (Conduct, Oppositional Defiant Disorder), Attention-Deficit Hyperactivity Disorder or any substance disorder (Alcohol abuse/dependence, Drug abuse/dependence). Internalizing disorders refer to the presence of any depressive disorder (Major Depression and Dysthymia) or studied anxiety disorder (Social Phobia, Separation Anxiety, Panic, Generalized Anxiety and Post Traumatic Stress).

Hurricane Exposure Questionnaire Questionnaires for caretakers and youth were adapted from an earlier study in PR about psychological consequences to a mud slides disaster in Puerto Rico (Bravo et al. 1990), and a hurricane in North Carolina (Norris and Kaniasty 1992). This measure was adapted for children using the La Greca and colleagues (1996) hurricane exposure questionnaire as a guide. Items assessed direct exposure to the child and to the family as an organized unit. Items pertaining to child exposure include life threat/loss (physical injury to the child or a significant other; loss of a family member or a person close to him/her; death of a pet), loss of material objects (toys, favorite books, and belongings) and child's disruption of everyday life (separation from family due to the hurricane; staying overnight out of home; still living out of home at time of interview). Parents provided information about their exposure to the hurricane (feeling afraid of dying or being hurt, becoming ill or injured during the hurricane) or loss or damage to their home (trees falling on the house, flooding, walls or roof falling, breakage of windows or door, total loss of the house).

Parents provided information for all participants, and children age 11 years and older were also interviewed. A continuous measure of exposure was developed by summing the counts for specific exposure experiences across the child and family unit (see Table 2 for items). If a child reported an experience a parent did not, it was included in the final total score. A dichotomous measure was also created that divided the sample into those who had no exposure experience and those with at least one exposure experience of either child or family exposure. Cronbach's alpha for this sample was 0.72 , indicating acceptable internal consistency.
Procedures

The confidentiality of the participants was protected as required by the University of Puerto Rico Institutional Review Board. All participants received thorough written and verbal explanations of the study and gave written assent/consent. The initial survey was performed from January 1999 through December 2000. The selection of primary caretaker as informant was based on who had close and regular contact with child for the longest time during the 6 months prior to the interview and was at least 18 years old ( $89.4 \%$ biological mother). The majority of the interviews with the exposed group took place in the home of a relative of the participants because many houses were destroyed by the hurricane. We used different interviewers for parent and child, and the interviewers were blinded to the results of each other's interviews. Interviews were audio-taped, and research assistants reviewed the entire tapes for all of the first and second interviews, plus $15 \%$ of a random selection of interviews to assure that interviewers were following the manualized training. They had a form they used to check fidelity to training. Research assistants also checked to ensure accurate data entry of what participants said. In data cleaning all outliers were evaluated to ensure they were not outliers due to poor interviewing.

\section{Analytic Strategy}

All data was checked for distributional properties, range violations, and logical inconsistencies. Apparent errors in data (such as range violations) were resolved by consulting the raw data, or assigned to missing if the problem could not be resolved. Distributional issues were resolved by using appropriate data transformations or trimming of values. Similar procedures were used in both data collection waves.

Descriptive information was obtained through frequencies and Chi Square analyses. Logistic regression was used for estimating the relationship between exposure and psychiatric disorders with adjustment for the sociodemographic variables of age, sex and perception of poverty level. These analyses were conducted with psychopathology measures obtained at T1 and T2. Models were estimated 
Table 2 Frequency of disaster exposure experiences (T1)

\begin{tabular}{lc}
\hline Exposure events & $n(\%)$ \\
\hline Child separation from family due to the hurricane & $53(3.0 \%)$ \\
Staying overnight out of home & $329(21.3 \%)$ \\
Still living out of home at time of T1 interview & $19(1.1 \%)$ \\
Severe physical injury to the child & $5(0.7 \%)$ \\
Severe physical injury to a significant other & $32(1.9 \%)$ \\
Death of a person close to the child & $23(1.3 \%)$ \\
Death of a pet & $92(6.9 \%)$ \\
Child's loss of objects (toys, books or other important belongings) & $409(25.5 \%)$ \\
Parent feeling afraid of dying or being hurt & $407(21.9 \%)$ \\
Parent becoming ill or injured & $107(6.8 \%)$ \\
Heavy loss due to the hurricane & $812(47.7 \%)$ \\
Trees falling on family home & $182(8.8 \%)$ \\
Flooding of home & $492(29.6 \%)$ \\
Roof falling & $318(20.8 \%)$ \\
Walls falling & $101(8.4 \%)$ \\
Breakage of windows or door & $366(23.0 \%)$ \\
Total loss of the house & $142(10.3 \%)$ \\
\hline
\end{tabular}

for predicting any psychiatric disorder, any externalizing disorder and any internalizing disorder for the full sample, and for younger children (age 4-10 years) and older youth (age 11-17 years) separately, to better understand the influence of age.

To test moderation, these models also included the estimation of interactions between exposure and the sociodemographic variables of sex, age (mean-centered) and poverty level. The procedures for testing moderation were consistent with recommendations by Baron and Kenny (1986) and Jaccard et al. (2006). In cases where the interactions terms were non-significant the model was trimmed by excluding the interaction terms and reestimating the model. To account for the complex sampling design, all logistic regression models were estimated using SUDAAN software release 8.0; Research Triangle Institute, Durham, NC. This software is capable of appropriate estimation of standard errors and hypothesis tests in samples obtained by a complex sample design.

\section{Results}

\section{Disaster Exposure}

Table 2 shows the specific hurricane-related events that children and their families experienced during the disaster. The most frequent events experienced include heavy loss due to the hurricane, flooding of the home, and children's loss of cherished objects. A significant number of parents reported feeling afraid of dying or being hurt. A relatively common child experience was staying overnight away from their home. One possible research question is whether or not child exposure should be examined separately from family exposure when examining the relation to psychopathology. We conducted preliminary analysis of this and found that both child and family exposure were related to internalizing disorder at T1, an only family exposure at T2. As the analysis did not clearly favor one form of exposure over the other, and because children are embedded within families, it made sense to us to combine them.

For the following results, the dichotomous disaster exposure variables were used. Nearly two-thirds $(60.2 \%)$ of the sample were exposed to the hurricane. (see Table 3). A comparison of the demographic characteristics of the exposed and the unexposed children using Chi Square analyses at approximately 18 months post-hurricane (T1) found that the sex and age distribution of the sub-samples were very similar for both types of exposure (see Table 3). However, as is usually seen in most disasters, people living in worse economic circumstances experienced more exposure to the disaster than those living in better economic circumstances $\left(\chi^{2}=(2,1886)=16.79 ; p<0.01\right)$, possibly due to damage to their homes, which may be of worse quality. Also, as indicated by Chi Square results, there was a significant difference between exposed and unexposed children on the presence of any disorder $\left(\chi^{2}=(1,1886)=\right.$ $7.14 ; p<0.01)$, any externalizing disorder $\chi^{2}=(1,1886)=$ $5.63 p<0.05)$, and any internalizing disorder $\chi^{2}=(1,1886)=$ $8.10 ; p<0.01)$. These analyses give preliminary support to the exposure-disorder relationship. However, as demographics are known to influence rates of psychopathology, their influence needs to be controlled when determining the relative influence of disaster exposure. 
Table 3 T1 Distribution of the exposed and unexposed children by demographics and psychopathology

\begin{tabular}{lcl}
\hline Demographics & $\begin{array}{l}\text { Unexposed } \\
(\%)\end{array}$ & $\begin{array}{l}\text { Exposed }^{\mathrm{a}} \\
n(\%)\end{array}$ \\
\hline Total & $768(39.8 \%)$ & $1,082(60.2 \%)$ \\
Sex & $401(50.1 \%)$ & $558(52.1 \%)$ \\
Male & $367(49.9 \%)$ & $524(47.9 \%)$ \\
Female & & \\
Age & $403(51.4 \%)$ & $551(48.8 \%)$ \\
$4-10$ & $365(48.6 \%)$ & $531(51.2 \%)$ \\
$11-17$ & & $521(45.9 \%)$ \\
Poverty*** & $465(60.0 \%)$ & $360(34.7 \%)$ \\
Live well & $245(32.0 \%)$ & $200(19.4 \%)$ \\
Check to check & $58(8.1 \%)$ & $202(18.5 \%)$ \\
Live poorly & $97(13.0 \%)$ & $144(12.9 \%)$ \\
Any psychiatric disorder** & $64(8.7 \%)$ & $106(11.0 \%)$ \\
Any externalizing disorder* & $44(5.8 \%)$ & \\
Any internalizing disorder** & & \\
\hline
\end{tabular}

${ }^{a}$ Exposed defined as experiencing at least one hurricane-related event ${ }^{*} p<0.05,{ }^{* *} p<0.01, * * * p<0.001$

The Influence of Disaster Exposure on Psychopathology

Results presented in Table 4 were produced using logistic regressions in which the exposure variables were continuous to indicate increasing levels of exposure (from none to severe), contrary to the previous analyses in which these variables were dichotomous. This change in the measurement model was done to increase the statistical power. For the total sample, the overall model predicting presence of any psychopathology at $\mathrm{T} 1$ was significant, Wald $\mathrm{F}(6)=$ 58.07, $p<0.001$, with living poorly as the significant predictor, Wald $\mathrm{F}(1)=5.90, p<0.05$. For $\mathrm{T} 2$, the model was also significant, Wald $\mathrm{F}(6)=77.75, p<0.01$, with living check to check (Wald $\mathrm{F}(1)=12.01, p<0.001$ ) and living poorly (Wald $\mathrm{F}(1)=4.49, p<0.05$ ) having significant relations to any psychopathology. Sex approached significance, with females being at lower risk of psychopathology at T2. Contrary to expectations, hurricane exposure was not a significant predictor in this model.

Likewise, the model for externalizing disorders was significant at $\mathrm{T} 1$, Wald $\mathrm{F}(6)=79.28, p<0.001$, and $\mathrm{T} 2$, Wald $\mathrm{F}(6)=64.39, p<0.01$. For both time points, sex (females were at lower risk; T1 Wald F (1)=4.04, $p<0.05$; T2 Wald F (1) 7.66, $p<0.01$ ), and poverty ( $\mathrm{T} 1$ living poorly: Wald $\mathrm{F}(1)=$ 13.84, $p<0.001$; T2 living check to check Wald $\mathrm{F}(1)=14.28$, $p<0.001$; T2 living poorly Wald $\mathrm{F}(1)=9.29 ; p<0.01)$, were the significant predictors. For internalizing disorders at T1, the model was significant, Wald $\mathrm{F}(6)=93.50, p<0.01$, and sex (females being at greater risk; Wald $\mathrm{F}(1)=4.46, p<0.05$ ), age (Wald $\mathrm{F}(1) 11.70, p<0.01$ ), and exposure (Wald $\mathrm{F}$ (1)-
13.48, $p<0.001)$ were the significant predictors. At $\mathrm{T} 2$, the model was again significant, Wald $\mathrm{F}(6)=97.28, p<0.001$, and sex had the only significant relation to risk for internalizing disorders (females were higher risk), Wald $\mathrm{F}$ $(1)=6.98, p<0.01$. In sum, there was partial support for our hypotheses. Disaster exposure, after controlling for demographics, was related to internalizing disorders at $\mathrm{T} 1$, but not to externalizing or any psychiatric disorder.

Assessment of Age Influences on the Exposure-Disorder Relationship

For the younger children (age 4-10 years), the overall models predicting presence of any psychopathology at $\mathrm{T} 1$ (Wald $\mathrm{F}(6)=43.73, p<0.001$ ) and $\mathrm{T} 2$ (Wald $\mathrm{F}(6)=$ $40.21, p<0.001)$ were significant. At $\mathrm{T} 1$, the significant predictors were sex (females lower risk; Wald $\mathrm{F}(1)=4.86$, $p<0.05$ ) and living poorly (Wald $\mathrm{F}(1)=12.19, p<0.001$ ). At $\mathrm{T} 2$ the only significant predictor was sex (Wald $\mathrm{F}(1)=$ 9.17, $p<0.01)$. With externalizing disorders, at $\mathrm{T} 1$ the overall model was significant (Wald F (6) $=46.84, p<$ 0.001 ) with the only significant predictors being poverty level, check to check (Wald F (1) 4.01, $p<0.05$ ) and living poorly (Wald F $(1)=14.21, p<0.001)$. Similar results were found at T2 (overall model Wald F (6) $=45.90, p<0.001$; poverty living check to check Wald $\mathrm{F}(1)=7.32, p<0.01$, living poorly Wald $\mathrm{F}(1)=7.55, p<0.01)$ with the addition of sex (females lower risk) as a significant predictor (Wald $\mathrm{F}(1)=6.53), p<0.05$. For internalizing disorders, at $\mathrm{T} 1$ the overall model was significant (Wald F $(6)=72.97, p<$ 0.001 ) and exposure was the significant predictor (Wald $\mathrm{F}$ $(1)=5.78, p<0.05)$. At T2, the overall model was significant (Wald $F(6)=38.44, p<0.001$ ) and sex was the only significant predictor (Wald $\mathrm{F}(1)=4.59, p<0.05$ ).

For the older youth (age 11-17 years), at T1 the models predicting any psychopathology and externalizing disorders were significant, Wald $\mathrm{F}(6)=27.38, p<0.001$ and Wald $\mathrm{F}$ $(6)=35.82, p<0.001$ respectively, but there were not any statistically significant predictors. At $\mathrm{T} 2$, the overall model predicting any psychopathology was significant, Wald $\mathrm{F}(6)=$ 43.36, $p<0.001$, and living check to check was a significant predictor, Wald $\mathrm{F}(1)=8.46, p<0.01$. For $\mathrm{T} 2$ externalizing disorders, the model was again significant, Wald $\mathrm{F}(6)=$ 33.57, $p<0.001$, with age (Wald $\mathrm{F}(1)=4.88, p<0.05$ ) and living paycheck to paycheck (Wald $\mathrm{F}(1)=7.78, p<0.01$ ) as significant predictors. Whereas, for internalizing disorders the model was significant (Wald $\mathrm{F}(6)=36.22, p<0.001$ ) and exposure (Wald F $(1)=7.66, p<0.01$ ) and child sex (females greater risk; Wald $\mathrm{F}(1)=11.54, p<0.001)$ were significantly related to the presence of an internalizing disorder at $\mathrm{T} 1$. At $\mathrm{T} 2$, the model was significant (Wald $\mathrm{F}(6)=54.07, p<0.001$ ) but there was not a significant predictor, although living paycheck to paycheck approached statistical significance. 
Table 4 Logistic regression results for exposure \& demographics in the prediction of psychopathology at T1 \& T2

\begin{tabular}{|c|c|c|c|c|c|c|}
\hline \multirow[t]{2}{*}{ Predictors } & \multicolumn{2}{|c|}{ Any psychiatric disorder } & \multicolumn{2}{|c|}{ Any externalizing disorder } & \multicolumn{2}{|c|}{ Any internalizing disorder } \\
\hline & $\begin{array}{l}\text { Time } 1 \\
\text { OR (CI) }\end{array}$ & $\begin{array}{l}\text { Time } 2 \\
\text { OR (CI) }\end{array}$ & $\begin{array}{l}\text { Time } 1 \\
\text { OR (CI) }\end{array}$ & $\begin{array}{l}\text { Time } 2 \\
\text { OR (CI) }\end{array}$ & $\begin{array}{l}\text { Time } 1 \\
\text { OR }(\mathrm{CI})\end{array}$ & $\begin{array}{l}\text { Time } 2 \\
\text { OR (CI) }\end{array}$ \\
\hline \multicolumn{7}{|c|}{ 4-17 years total sample } \\
\hline $\begin{array}{l}\text { Gender } \\
\text { Female }\end{array}$ & $\begin{array}{l}0.89 \\
(0.63-1.25)\end{array}$ & $\begin{array}{l}0.70^{+} \\
(0.48-1.01)\end{array}$ & $\begin{array}{l}0.64 * \\
(0.42-0.99)\end{array}$ & $\begin{array}{l}0.56^{* *} \\
(0.37-0.84)\end{array}$ & $\begin{array}{l}1.62 * \\
(1.03-2.54)\end{array}$ & $\begin{array}{l}0.92 \\
(0.52-1.61)\end{array}$ \\
\hline Age & $\begin{array}{l}1.03 \\
(0.99-1.08)\end{array}$ & $\begin{array}{l}1.01 \\
(0.97-1.05)\end{array}$ & $\begin{array}{l}0.99 \\
(0.95-1.03)\end{array}$ & $\begin{array}{l}0.96 \\
(0.92-1.01)\end{array}$ & $\begin{array}{l}1.08 * * * \\
(1.03-1.14)\end{array}$ & $\begin{array}{l}1.08^{* *} \\
(1.02-1.14)\end{array}$ \\
\hline $\begin{array}{l}\text { Poverty } \\
\text { Chk to Chk }\end{array}$ & $\begin{array}{l}1.27 \\
(0.88-1.83)\end{array}$ & $\begin{array}{l}2.08 * * * \\
(1.37-3.14)\end{array}$ & $\begin{array}{l}1.52^{+} \\
(1.00-2.30)\end{array}$ & $\begin{array}{l}2.49 * * * \\
(1.55-4.01)\end{array}$ & $\begin{array}{l}1.23 \\
(0.79-1.92)\end{array}$ & $\begin{array}{l}1.69 \\
(0.89-3.21)\end{array}$ \\
\hline Live poorly & $\begin{array}{l}1.72 * \\
(1.11-2.67)\end{array}$ & $\begin{array}{l}1.73 * \\
(1.04-2.88)\end{array}$ & $\begin{array}{l}2.41 * * * \\
(1.51-3.84)\end{array}$ & $\begin{array}{l}2.52 * * \\
1.39-4.60\end{array}$ & $\begin{array}{l}0.98 \\
(0.53-1.80)\end{array}$ & $\begin{array}{l}1.02 \\
(0.53-1.96)\end{array}$ \\
\hline Exposure $^{\mathrm{a}}$ & $\begin{array}{l}1.05 \\
(0.99-1.11)\end{array}$ & $\begin{array}{l}1.01 \\
(0.96-1.07)\end{array}$ & $\begin{array}{l}1.02 \\
(0.96-1.08)\end{array}$ & $\begin{array}{l}0.97 \\
(0.87-1.08)\end{array}$ & $\begin{array}{l}1.14 * * * \\
(1.06-1.22)\end{array}$ & $\begin{array}{l}1.07^{+} \\
(0.99-1.16)\end{array}$ \\
\hline \multicolumn{7}{|c|}{ 4-10 years subsample } \\
\hline $\begin{array}{l}\text { Sex: } \\
\text { Female }\end{array}$ & $\begin{array}{l}0.57 * \\
(0.34-0.94)\end{array}$ & $\begin{array}{l}0.44 * * \\
(0.26-0.75)\end{array}$ & $\begin{array}{l}0.58 \\
(0.33-1.04)\end{array}$ & $\begin{array}{l}0.47 * \\
(0.27-0.84)\end{array}$ & $\begin{array}{l}0.74 \\
(0.36-1.54)\end{array}$ & $\begin{array}{l}0.33 * \\
(0.12-0.91)\end{array}$ \\
\hline Age & $\begin{array}{l}1.03 \\
(0.92-1.14)\end{array}$ & $\begin{array}{l}0.92 \\
(0.80-1.06)\end{array}$ & $\begin{array}{l}1.01 \\
(0.90-1.14)\end{array}$ & $\begin{array}{l}0.90 \\
(0.77-1.06)\end{array}$ & $\begin{array}{l}1.13 \\
(0.93-1.38)\end{array}$ & $\begin{array}{l}1.04 \\
(0.85-1.29)\end{array}$ \\
\hline $\begin{array}{l}\text { Poverty } \\
\text { Chk to Chk }\end{array}$ & $\begin{array}{l}1.52 \\
(0.95-2.42)\end{array}$ & $\begin{array}{l}1.80^{+} \\
(0.96-3.38)\end{array}$ & $\begin{array}{l}1.69 * \\
(1.01-2.85)\end{array}$ & $\begin{array}{l}2.33 * * \\
(1.26-4.32)\end{array}$ & $\begin{array}{l}1.43 \\
(0.71-2.88)\end{array}$ & $\begin{array}{l}0.77 \\
(0.25-2.36)\end{array}$ \\
\hline Live poorly & $\begin{array}{l}2.84 * * *(1.58- \\
5.11)\end{array}$ & $\begin{array}{l}2.17^{+}(0.92- \\
5.10)\end{array}$ & $\begin{array}{l}3.23 * * * * \\
5.97)\end{array}$ & $\begin{array}{l}3.26 * *(1.40- \\
7.62)\end{array}$ & $\begin{array}{l}1.22(0.49- \\
3.07)\end{array}$ & $\begin{array}{l}0.79(0.17- \\
3.60)\end{array}$ \\
\hline Exposure $^{a}$ & $\begin{array}{l}1.01 \\
(0.95-1.07)\end{array}$ & $\begin{array}{l}0.98 \\
(0.84-1.14)\end{array}$ & $\begin{array}{l}1.01 \\
(0.94-1.08)\end{array}$ & $\begin{array}{l}0.93 \\
(0.79-1.10)\end{array}$ & $\begin{array}{l}1.11 * \\
(1.02-1.21)\end{array}$ & $\begin{array}{l}1.06 \\
(0.89-1.25)\end{array}$ \\
\hline \multicolumn{7}{|c|}{ 11-17 years subsample } \\
\hline $\begin{array}{l}\text { Sex } \\
\text { Female }\end{array}$ & $\begin{array}{l}1.30 \\
(0.83-2.03)\end{array}$ & $\begin{array}{l}0.90 \\
(0.56-1.46)\end{array}$ & $\begin{array}{l}0.71 \\
(0.40-1.27)\end{array}$ & $\begin{array}{l}0.62 \\
(0.35-1.10)\end{array}$ & $\begin{array}{l}2.75^{* * *} \\
(1.53-4.93)\end{array}$ & $\begin{array}{l}1.27 \\
(0.64-2.49)\end{array}$ \\
\hline Age & $\begin{array}{l}1.08 \\
(0.96-1.22)\end{array}$ & $\begin{array}{l}0.91 \\
(0.81-1.02)\end{array}$ & $\begin{array}{l}1.03 \\
(0.89-1.20)\end{array}$ & $\begin{array}{l}0.86 \\
(0.75-0.98)\end{array}$ & $\begin{array}{l}1.04 \\
(0.91-1.20)\end{array}$ & $\begin{array}{l}0.95 \\
(0.79-1.12)\end{array}$ \\
\hline $\begin{array}{l}\text { Poverty } \\
\text { Chk to Chk }\end{array}$ & $\begin{array}{l}1.04 \\
(0.63-1.73)\end{array}$ & $\begin{array}{l}2.17 * * \\
(1.28-3.68)\end{array}$ & $\begin{array}{l}1.33 \\
(0.71-2.48)\end{array}$ & $\begin{array}{l}2.50 \\
(1.31-4.78)\end{array}$ & $\begin{array}{l}1.06 \\
(0.59-1.92)\end{array}$ & $\begin{array}{l}2.10^{+} \\
(0.97-4.57)\end{array}$ \\
\hline Live poorly & $\begin{array}{l}1.16 \\
(0.58-2.34)\end{array}$ & $\begin{array}{l}1.52 \\
(0.79-2.95)\end{array}$ & $\begin{array}{l}1.76 \\
(0.79-3.95)\end{array}$ & $\begin{array}{l}2.03 \\
(0.84-4.91)\end{array}$ & $\begin{array}{l}0.81 \\
(0.34-1.94)\end{array}$ & $\begin{array}{l}1.12 \\
(0.54-2.33)\end{array}$ \\
\hline Exposure & $\begin{array}{l}1.08^{+} \\
(0.99-1.18)\end{array}$ & $\begin{array}{l}1.03 \\
(0.95-1.13)\end{array}$ & $\begin{array}{l}1.02 \\
(0.92-1.13)\end{array}$ & $\begin{array}{l}1.00 \\
(0.90-1.11)\end{array}$ & $\begin{array}{l}1.17 * * \\
(1.05-1.29)\end{array}$ & $\begin{array}{l}1.08 \\
(0.95-1.24)\end{array}$ \\
\hline $\begin{array}{l}\text { Exposure } \\
\text { X Age }\end{array}$ & $\begin{array}{l}0.97 * \\
(0.94-1.00)\end{array}$ & $\begin{array}{l}0.94 * * \\
0.90-0.97\end{array}$ & - & - & $\begin{array}{l}0.97+ \\
(0.93-1.00)\end{array}$ & - \\
\hline
\end{tabular}

CI 95\% confidence interval; Dx diagnosis

${ }^{a}$ Exposure is defined in this set of analyses as the sum of hurricane-related events

${ }^{\mathrm{b}}$ Exposure $\mathrm{x}$ age was the only statistically significant exposure $\mathrm{X}$ demographics interaction found

${ }^{+} p<0.10, * p<0.05, * * p<0.01, * * * p<0.001$

In sum, consistent with results for the full sample, for both younger children and older youth, the relative influence of disaster exposure controlling for demographics was related to internalizing disorders at T1 only. Age differences were found for the demographic predictors, but not completely as expected. For example, for younger children, being female was related to lower risk for any disorder, externalizing disorders, and internalizing disorders. But for older youth, being female increased risk for an internalizing disorder. Poverty had a significant relation to externalizing disorders for younger children, but not older youth. 
Moderators of Exposure

Separate analyses testing for moderation between demographics and exposure on predicting any psychopathology, externalizing disorders, and internalizing disorders were conducted. Results indicated that the sex, poverty, and age by exposure interactions were generally non-significant (results not shown). For the older youth, there was a significant exposure by age interaction for any psychopathology at $\mathrm{T} 1$ and $\mathrm{T} 2$, and one that approached significance for internalizing disorders at $\mathrm{T} 1$ (see Table 4). This indicates that for older youth, the effect of exposure on odds of having a psychiatric disorder increased with age.

\section{Rates of Specific Internalizing Disorders}

Although we did not have enough power to run logistic regression models for specific disorders, as the relation between exposure and internalizing disorders was significant, we wanted to provide a comparison between exposed and unexposed children on rates of specific internalizing disorders (Table 5). Chi square analyses showed significant differences between exposed and unexposed groups for Major Depression $\left(\chi^{2}(1)=5.58, p<0.05\right)$, Social Phobia $\left(\chi^{2}(1),=4.42, p<0.05\right)$, and Separation Anxiety $\left(\chi^{2}(1),=4.85, p<0.05\right)$ at T1. Interestingly, there was no difference between groups for PTSD. For $\mathrm{T} 2$, the Chi squares were non-significant, although it approached significance for Social Phobia $(p<0.055)$.

\section{Discussion}

We examined the mental health consequences of a disaster among children and adolescents using two post-disaster diagnostic assessments (at approximately 18 and 30 months) and obtained results that can contribute to the field. First, we found evidence that children's disaster-related distress manifested as internalizing disorders, not externalizing disorders. This extends beyond much of previous disaster mental health research that predominantly focused exclusively on PTSD and rarely assessed externalizing reactions. An exploration of rates of specific internalizing disorders found elevated rates of Major Depression, Social Phobia, and Separation Anxiety, but not PTSD. We also found consistency in results across the age range assessed. We found that the poor were more likely to be exposed to the hurricane, but did not find a moderating effect of poverty and exposure on the development of a disorder. The only moderator was age by exposure for older youth. Finally, many of the exposed youth recovered by 30 months postdisaster, as there was no longer a significant difference between exposed and non-exposed groups on rates of disorder at that time point. In the following sections, we discuss these findings in greater depth.
Post-Disaster Psychopathology

We found a relationship between level of exposure to a natural disaster and the likelihood of internalizing disorders, but not externalizing disorders, at 18 months post-disaster. This was consistent across ages. This indicates that this relation is not simply a result of disaster research methodology (a bias towards assessing internalizing disorders, like depression and PTSD, in trauma and disaster research), but may reflect reality. It may be that externalizing reactions to stress may be consciously suppressed by youth so as not to further disrupt the family that is already coping with an extraordinary stressor. Research on post-disaster externalizing disorders is very limited, thus this study fills a gap. One study on post-disaster reactive aggression found that the relation between hurricane exposure and reactive aggression was mediated by PTSD symptoms and emotion dysregulation (Marsee 2008). As we did not find a difference between exposed and unexposed on rates of PTSD, which were low in general in this sample, that may be one reason why we did not find increased rates of externalizing disorders.

Other disaster studies (e.g., Vogel and Vernberg 1993; Weems et al. 2007, 2010; Yule, 2001) have also found that children usually present psychological distress that is manifested as internalizing symptomatology, such as depression and anxiety symptoms. We found that disaster exposure was not only related to internalizing symptoms, but to internalizing psychiatric disorders since these symptoms were associated with significant impairment and/or distress and other DSM-IV criteria (i.e., duration). More importantly, this psychopathology tends to persist for a rather long period of time (up to 18 months after the event). Thus, it is a step forward to acknowledge that many children will suffer from a range of anxiety and depressive disorders for some time after a hurricane and is consistent with research on youth after Hurricane Katrina (Weems et al. 2010). By 30 months post-disaster, youth appeared to have recovered as there no longer was a significant difference between the hurricane exposed and non-exposed groups. Most disaster research supports that distress decreases with time, with the notable exception of recovery after Hurricane Katrina (Kessler et al. 2008; Weems et al. 2010).

Traumatic events may be potential pathways to the development of phobias and other anxiety-based disorders in youth (see Silverman and La Greca 2002). Likewise, the presence of depressive disorders has been observed in child victims of disasters (Goenjian et al. 2001). Our findings are consistent with this, as we found elevated rates of Major Depression, Social Phobia, and Separation Anxiety. In contrast to prior research, we did not find elevated rates of PTSD, compared to many U.S. studies. Hurricane Georges was a Category 2 hurricane, whereas many of the hurricanes studied in the U.S. were Category 5. Increased severity of exposure is 
Table 5 Comparison of disaster exposure and specific internalizing disorders at $\mathrm{T} 1$ and $\mathrm{T} 2$

\begin{tabular}{|c|c|c|c|c|}
\hline \multirow[t]{2}{*}{ Disorders } & \multicolumn{2}{|l|}{ Time 1} & \multicolumn{2}{|l|}{ Time 2} \\
\hline & $\begin{array}{l}\text { Unexposed } \\
n(\mathrm{w} \%) \mathrm{CI}\end{array}$ & $\begin{array}{l}\text { Exposed } \\
n \text { w\% (CI) }\end{array}$ & $\begin{array}{l}\text { Unexposed } \\
n \mathrm{w} \%(\mathrm{CI})\end{array}$ & $\begin{array}{l}\text { Exposed } \\
n \text { w\% (CI) }\end{array}$ \\
\hline \multirow[t]{2}{*}{ PTSD } & $3(0.8 \%)$ & $8(0.8 \%)$ & $2(0.2 \%)$ & $6(0.5 \%)$ \\
\hline & $0.2-2.8 \%$ & $0.3-2.0 \%$ & $0.1-0.8 \%$ & $0.2-1.2 \%$ \\
\hline \multirow[t]{2}{*}{ Major depression } & $9(1.3 \%)^{*}$ & $30(4.0 \%)^{*}$ & $14(1.7 \%)$ & $22(2.2 \%)$ \\
\hline & $06 .-2.7 \%$ & $2.5-6.3 \%$ & $0.9-3.1 \%$ & $1.4-3.5 \%$ \\
\hline \multirow[t]{2}{*}{ Dysthimia } & $4(0.5 \%)$ & $7(0.5 \%)$ & 0 & 1 \\
\hline & $0.2-1.4 \%$ & $0.2-1.4 \%$ & - & - \\
\hline \multirow[t]{2}{*}{ Generalized anxiety } & $12(1.4 \%)$ & $22(2.8 \%)$ & $5(0.4 \%)$ & $10(1.0 \%)$ \\
\hline & $0.7-2.7 \%$ & $1.7-4.8 \%$ & $0.2-0.9 \%$ & $0.5-1.9 \%$ \\
\hline \multirow[t]{2}{*}{ Social phobia } & $10(1.4 \%)^{*}$ & $32(3.3 \%)^{*}$ & $7(0.7 \%)^{\mathrm{a}}$ & $18(1.9 \%)^{\mathrm{a}}$ \\
\hline & $0.7-2.8 \%$ & $2.2-4.9 \%$ & $0.3-1.4 \%$ & $1.0-3.4 \%$ \\
\hline \multirow[t]{2}{*}{ Separation anxiety } & $19(1.9 \%)^{*}$ & $46(3.9 \%)^{*}$ & $12(1.7 \%)$ & $28(2.7 \%)$ \\
\hline & $1.1-3.2 \%$ & $2.7-5.6 \%$ & $0.9-3.4 \%$ & $1.7-4.4 \%$ \\
\hline \multirow[t]{2}{*}{ Panic } & $2(0.2 \%)$ & $6(0.7 \%)$ & $3(0.4 \%)$ & $3(0.3 \%)$ \\
\hline & $0.0-0.8 \%$ & $0.3-1.9 \%$ & $0.1-1.4 \%$ & $0.1-1.3 \%$ \\
\hline
\end{tabular}

$w \%$ weighted percentage; $C I$ $95 \%$ confidence interval

${ }^{*} p<0.05,{ }^{\mathrm{a}} p<0.06$
Implications for Clinical Intervention Post-Disaster

Although for some children the psychopathological effects of a disaster diminish with time, our data show that some will develop anxiety and/or depressive disorders that tend to persist over time. It is clear that screening and intervention for the range of internalizing disorders must be emphasized in the recovery and reconstruction phase. A proactive intervention may be to coordinate effective psychological services to help children recover from initial hurricane-related internalizing distress and thus prevent the development of chronic internalizing psychopathology that we find in this study.

The National Child Traumatic Stress Network (NCTSN) continually provides updates and access to training materials for empirically-supported trauma treatment, and is a valuable resource (see http://www.nctsnet.org/nccts/nav.do? pid=ctr_train_archive). Psychological First Aid is one example of an evidence-informed prevention intervention that can be applied in the immediate aftermath of a disaster (Vernberg et al. 2008), and is available through NCTSN. School-based services can be a public mental health effort to mitigate trauma reactions in a setting with low potential for perceived stigma. This has been offered in the aftermath of the 9/11/01 terrorist attacks and Hurricanes Katrina and Rita (see Dean et al. 2008, for a discussion of implementation and lessons learned). For non-transitory post-disaster distress, a specific cognitive-behavioral treatment program has been developed for children to be used within the school-setting, Cognitive Behavioral Interventions for Trauma in Schools (Stein et al. 2003). This can be applied as an intervention for those at risk of developing psychopathology as it is used to alleviate symptoms of anxiety, 
depression, and traumatic stress. Additional post-disaster traumatic stress and grief-oriented interventions for children also show some empirical support (Goenjian et al. 1997; Salloum and Overstreet 2008). Given this level of psychopathology in some disaster survivors, referrals for psychiatric services, such as medication, may also be indicated.

\section{Strengths and Limitations}

This longitudinal study improved upon much prior disaster mental health research in children and adolescents. It is based on a large, randomly-selected, representative sample of a relatively homogeneous Latino/a population living in a clearly-defined geographical location (an island); it includes relatively large and evenly distributed age and sex subgroups; and employs structured DSM-IV assessments in two post-disaster periods. This latter point improves upon prior disaster studies by assessing psychopathology beyond PTSD, at the disorder-level, which includes actual impairment in functioning and/or distress resulting from the symptoms, as well as duration. We also had a non-exposed comparison group that allowed a more stringent test of the exposure-disorder relationship.

Consistent with most disaster research, our main limitation is that we do not have measures of predisaster psychopathology. Therefore, we could not control for prior mental health in predicting post-disaster internalizing disorders. Research has shown that prior mental health increases risk of post-disaster psychopathology (Silverman and La Greca 2002; Weems et al. 2007). Nevertheless, the main analytic strategy used, that took into account youth's sex, age and perceived poverty level, tends to minimize this limitation. Also, we do not have data prior to 18 months, or adverse events that can be dated as subsequent to the disaster. We did not ask children if they feared they may lose their own life, but this would be beneficial to include.

In conclusion, child-focused disaster research is still a relatively new area of study, whereas research on the adjustment and treatment of adult disaster victims is more well-developed. This study extended prior work and applied rigorous methodology to further our understanding of the exposure-disorder relationship among children and youth. We hope to see more longitudinal studies, employing three or more waves of data collection that explore how traumatic exposure at different developmental periods affects subsequent development. Equally important, future research also needs to examine in greater depth the aspects of the recovery environment that promote or hinder children's mental health recovery following a natural disaster. With research using three waves of data, more stringent and causal tests of mediation among risk and protective factors that influence the exposure-disorder relationship can be examined. This research is crucial in order to best inform prevention, early intervention, and treatment efforts that may focus on the family, school, peer, and community environments.

Open Access This article is distributed under the terms of the Creative Commons Attribution Noncommercial License which permits any noncommercial use, distribution, and reproduction in any medium, provided the original author(s) and source are credited.

\section{References}

Adams, R. E., \& Boscarino, J. A. (2005). Differences in mental health outcomes among Whites, African Americans, and Hispanics after a community disaster. Psychiatry, 68, 250-265. doi:10.1521/ psyc.2005.68.3.250.

Angold, A., Costello, E. J., Farmer, E. M. Z., Burns, B. J., \& Erkanli, A. (1999). Impaired but undiagnosed. Journal of the American Academy of Child \& Adolescent Psychiatry, 38, 129-137. doi:10.1097/00004583-199902000-00011.

Baron, R. M., \& Kenny, D. A. (1986). The moderator-mediator variable distinction in social psychological research: conceptual, strategic, and statistical considerations. Journal of Personality \& Social Psychology, 51, 1173-1182. doi:10.1037/0022-3514.51.6.1173.

Bravo, M., Rubio-Stipec, M., Canino, G., Woodbury, M., \& Ribera, J. (1990). The psychological sequelae of disaster stress prospectively and retrospectively evaluated. American Journal of Community Psychology, 18, 661-680. doi:10.1007/BF00931236.

Bravo, M., Canino, G., Rubio-Stipec, M., \& Woodbury, M. (1991). A cross-cultural adaptation of a diagnostic instrument: the DIS adaptation in Puerto Rico. Culture, Medicine, and Psychiatry, 15, 1-18. doi:10.1007/BF00050825.

Bravo, M., Ribera, J., Rubio-Stipec, M., Canino, G., Shrout, P., Ramírez, R., et al. (2001). Test-retest reliability of the Spanish version of the Diagnostic Interview Schedule for Children (DISC-IV). Journal Abnormal Child Psychology, 29, 433-444. doi:10.1023/A:1010499520090.

Brislin, R. W., Lonner, W. E., \& Thorndike, R. M. (1973). Crosscultural research methods. New York: Wiley.

Bullinger, M., Alonso, J., Apolone, G., Leplege, A., Sullivan, M., Wood-Dauphinee, S., et al. (1998). Translating health status questionnaires and evaluating their quality: the IQOLA project approach. Journal of Clinical Epidemiology, 51, 913-923. doi:10.1016/S0895-4356(98)00082-1.

Canino, G., \& Bravo, M. (1994). The adaptation and testing of diagnostic and outcome measures for cross-cultural research. International Review of Psychiatry, 281-286. doi:10.3109/ 09540269409023267

Canino, G., Shrout, P. E., Rubio-Stipec, M., Bird, H. R., Bravo, M., Ramirez, R., et al. (2004). The DSM-IV rates of child and adolescent disorders in Puerto Rico: prevalence, correlates, service use, and the effects of impairment. Archives of General Psychiatry, 61, 85-93. doi:10.1001/archpsyc.61.1.85.

Center for Disease Control and Prevention. (1998). Deaths associated with Hurricane Georges-Puerto Rico. Journal of the American Medical Association, 280, 1736-1737.

Davidson, L. M., \& Baum, A. (1986). Chronic stress and posttraumatic stress disorders. Journal of Consulting and Clinical Psychology, 54, 303-308. doi:10.1037/0022-006X.54.3.303.

Dean, K. L., Langley, A. K., Kataoka, S. H., Jaycox, L. H., Wong, M., \& Stein, B. D. (2008). School-based disaster mental health services: clinical, policy, and community challenges. Profession- 
al Psychology: Research and Practice, 39, 52-52. doi:10.1037/ 0735-7028.39.1.52.

Duarte, C. S., Bird, H. R., Shrout, P. E., Wu, P., Lewis-Fernandez, R., Shen, S., et al. (2008). Culture and psychiatric symptoms in Puerto Rican children: longitudinal results from one ethnic group in two contexts. Journal of Child Psychology \& Psychiatry, 49, 563-572. doi:10.1111/j.1469-7610.2007.01863.x.

Goenjian, A. K., Karayan, I., Pynoos, R. S., \& Minassian, D. (1997). Outcome of psychotherapy among early adolescents after trauma. American Journal of Psychiatry, 154, 536-536.

Goenjian, A. K., Molina, L., Steinberg, A. M., \& Fairbanks, L. A. (2001). Posttraumatic stress and depressive reactions among Nicaraguan adolescents after Hurricane Mitch. The American Journal of Psychiatry, 158, 788-794. doi:10.1176/appi.ajp.158.5.788.

International Strategy for Disaster Reduction, n.d. Disaster Occurrence. Retrieved on 4/25/2009 from http://www.unisdr.org/disas ter-statistics/occurrence-trends-century.htm

Jaccard, J., Guilamo-Ramos, V., Johansson, M., \& Bouris, A. (2006). Multiple regression analyses in clinical child and adolescent psychology. Journal of Clinical Child and Adolescent Psychology, 35, 456-479.

Kessler, R. C., Galea, S., Gruber, M. J., Sampson, N. A., Ursano, R. J., \& Wessely, S. (2008). Trends in mental illness and suicidality after Hurricane Katrina. Molecular Psychiatry, 13, 374-384. doi:10.1038/sj.mp.4002119.

Kish, L. (1965). Survey. New York: Wiley.

La Greca, A. M., \& Prinstein, M. J. (2002). Hurricanes and earthquakes. In A. M. La Greca, W. K. Silverman, E. M. Vernberg, \& M. C. Roberts (Eds.), Helping children cope with disasters and terrorism (pp. 107-138). Washington: American Psychological Association.

La Greca, A. M., Silverman, W. K., Vernberg, E. M., \& Prinstein, M. J. (1996). Symptoms of posttraumatic stress alter Hurricane Andrew: a prospective study. Journal of Consulting and Clinical Psychology, 64, 712-723. doi:10.1037/0022-006X.64.4.712.

La Greca, A. M., Silverman, W. K., \& Wasserstein, S. B. (1998). Children's predisaster functioning as a predictor of posttraumatic stress following Hurricane Andrew. Journal of Consulting and Clinical Psychology, 66, 883-892. doi:10.1037/0022-006X.66.6.883.

La Greca, A. M., Silverman, W. K., Vernberg, E. M., \& Roberts, M. C. (Eds.). (2002). Helping children cope with disasters and terrorism. Washington: American Psychological Association.

Marsee, M. A. (2008). Reactive aggression and posttraumatic stress in adolescents affected by Hurricane Katrina. Journal of Clinical Child and Adolescent Psychology, 37, 519-529. doi:10.1080/ 15374410802148152.

Matías-Carrelo, L. E., Chávez, L. M., Negrón, G., Canino, G., Aguilar-Gaxiola, S., \& Hoppe, S. (2003). The Spanish translation and cultural adaptation of five mental health outcome measures. Culture, Medicine and Psychiatry, 27, 291-313. doi:10.1023/ A:1025399115023.

Norris, F. H., \& Kaniasty, K. (1992). Reliability of delayed selfreports in disaster research. Journal of Traumatic Stress, 5, 575588. doi: $10.1002 /$ jts. 2490050407.

Norris, F. H., Friedman, M. J., \& Watson, P. J. (2002a). 60,000 disaster victims speak: Part II. Summary and implications of the disaster mental health research, 1981-2001. Psychiatry, 65, 240 260. doi:10.1521/psyc.65.3.240.20169.

Norris, F. H., Friedman, M. J., Watson, P. J., \& Byrne, C. M. (2002b). 60,000 disaster victims speak: Part 1. An empirical review of the empirical literature, 1981-2001. Psychiatry, 65, 207-239. doi:10.1521/psyc.65.3.207.20173.
Norris, F. H., Galea, S., Friedman, M. J., \& Watson, P. (2006). Methods for disaster mental health research. New York: Guilford.

Perilla, J. L., Norris, F. H., \& Lavizzo, E. A. (2002). Ethnicity, culture, and disaster response, identifying and explaining ethnic differences in PTSD six months after Hurricane Andrew. Journal of Social and Clinical Psychology, 21, 20-45. doi:10.1521/ jscp.21.1.20.22404.

Prewitt, J. (1999). Stressors in Puerto Rican children as a result of Hurricane Georges. Education, 119, 658-662.

Salloum, A., \& Overstreet, S. (2008). Evaluation of individual and group grief and trauma interventions for children post disaster. Journal of Clinical Child and Adolescent Psychology, 37, 459507. doi:10.1080/15374410802148194.

Schwab-Stone, M., Fallon, T., Briggs, M., \& Crowther, B. (1994). Reliability of diagnostic reporting for children aged 6-11 years: a test-retest study of the Diagnostic Interview Schedule for ChildrenRevised. American Journal of Psychiatry, 151, 1048-1054.

Shaffer, D., Fisher, P., Lucas, C. P., Dulcan, M. K., \& Schwab-Stone, M. E. (2000). NIMH Diagnostic Interview Schedule for Children Version IV (NIMH DISC-IV): description, differences from previous versions, and reliability of some common diagnoses. Journal of the American Academy Child Adolescents Psychiatry, 39, 28-38. doi:10.1097/00004583-200001000-00014.

Silverman, W. K., \& La Greca, A. M. (2002). Children experiencing disasters: Definitions, reactions, and predictions of outcomes. In A. M. La Greca, W. K. Silverman, E. M. Vernberg, \& M. C. Roberts (Eds.), Helping children cope with disasters and terrorism (pp. 11-33). Washington: American Psychological Association. doi:10.1037/10454-001.

Stein, B. D., Jaycox, L. H., Kataoka, S. H., Wong, M., Tu, W., Elliott, M. N., et al. (2003). A mental health intervention for schoolchildren exposed to violence: a randomized controlled trial. Journal of the American Medical Association, 290, 603-611.

Vernberg, E. M. (2002). Intervention approaches following disaster. In La Greca, A. M., Silverman W. K., Vernberg, E. M \& Roberts, M. C.(Eds.), Helping Children Cope with Disasters and Terrorism. (pp. 55-72). Washington, DC: American Psychological Association.

Vernberg, E. M., La Greca, A. M., Silverman, W. K., \& Prinstein, M. J. (1996). Prediction of posttraumatic stress symptoms in children after Hurricane Andrew. Journal of Abnormal Psychology, 105, 237-248. doi:10.1037/0021-843X.105.2.237.

Vernberg, E. M., Steinberg, A. M., Jacobs, A. K., Brymer, M. J., Watson, P. J., Osofsky, J. D., et al. (2008). Innovations in disaster mental health: psychological first aid. Professional Psychology: Research and Practice, 39, 381-381. doi:10.1037/a0012663.

Vogel, J. M., \& Vernberg, E. M. (1993). Children's psychological responses to disasters. Journal of Clinical Child Psychology, 22, 464-484. doi:10.1207/s15374424jccp2204 7.

Weems, C. F., Pina, A. A., Costa, N. M., Watts, S. E., Taylor, L. K., \& Cannon, M. F. (2007). Predisaster trait anxiety and negative affect predict posttraumatic stress in youths after Hurricane Katrina. Journal of Consulting and Clinical Psychology, 75, 154-159. doi:10.1037/0022-006X.75.1.154.

Weems, C. F., Taylor, L. K., Cannon, M. F., Marino, R. C., Romano, D. M., Scott, B. G., et al. (2010). Posttraumatic stress, context, and the lingering effects of the Hurricane Katrina disaster among ethnic minority youth. Journal of Abnormal Child Psychology, 38, 49-56. doi:10.1007/s10802-009-9352-y.

Yule, W. (2001). Post-traumatic stress in children and adolescents. International Review of Psychiatry, 13, 194-200. doi:10.1080/ 09540260120074064. 